\title{
Primeiro registro de Antillorbis nordestensis (Lucena) (Mollusca, Gastropoda, Planorbidae) para a Ilha Grande, Angra dos Reis, Rio de Janeiro
}

\author{
Sonia Barbosa dos Santos ${ }^{1}$ \\ Daniele Pedrosa Monteiro ${ }^{2}$ \\ Mônica Ammon Fernandez ${ }^{3}$ \\ Silvana Carvalho Thiengo ${ }^{3}$
}

\begin{abstract}
First record of Antillorbis nordestensis (Lucena) (Mollusca, Gastropoda, Planorbidae) to Ilha Grande, Angra dos Reis, Rio de Janeiro. A malacological survey has been done by the senior author in Ilha Grande, State of Rio de Janeiro, since 1996. Up to this date the only freshwater gastropods found were specimens of Antillorbis nordestensis (Lucena, 1954). The snails were collected at a swampy area situated behind the late Penal Colony Cândido Mendes (Ilha Grande Prison).

KEY WORDS. Mollusca, Planorbidae, Antillorbis nordestensis, distribution
\end{abstract}

Desde 1996 a autora senior vem realizando o levantamento da malacofauna presente na área do CEADS (Centro de Estudos Ambientais e Desenvolvimento Sustentado) da Universidade do Estado do Rio de Janeiro (UERJ), situado na Vila Dois Rios, Ilha Grande, onde localizava-se a Colônia Penal Cândido Mendes (Presídio da Ilha Grande), hoje desativada.

A região em estudo apresenta fragmentos de Mata Atlântica em diversos estágios de regeneração, com dois rios principais (Rio Barra Grande e Rio Barra Pequena), além de diversos riachos de pequeno porte que descem das montanhas, formando brejos em alguns pontos da baixada.

Antillorbis nordestensis, originalmente descrita como Tropicorbis nordestensis por LUCENA (1954) para o Estado de Pernambuco, é espécie de pequeno porte, alcançando no máximo $5 \mathrm{~mm}$ de diâmetro. A concha apresenta perióstraco amarelado claro, com quatro voltas arredondadas que crescem rapidamente em diâmetro; o lado direito tende a ser aplanado, pouco côncavo, com o giro central superficial; o lado esquerdo forma uma concavidade ampla e profunda; a sutura é bem marcada nos dois lados; abertura ovóide, ampla, geralmente defletida para a esquerda. PARAENSE \& DESLANDES (1958) e PARAENSE (1975) forneceram descrições deta-

1) Laboratório de Malacologia, Setor de Zoologia, Instituto de Biologia Roberto Alcântara Gomes (IBRAG), Universidade do Estado do Rio de Janeiro. Rua São Francisco Xavier 524, 20550-900 Rio de Janeiro, Brasil. E-mail: sbsantos@uerj.br

2) Bolsista de Iniciação Científica UERJ/PIBC/SR-2.

3) Departamento de Malacologia, Fundação Instituto Oswaldo Cruz. Avenida Brasil 4365, Caixa Postal 926, 21045-900 Rio de Janeiro, Brasil. 


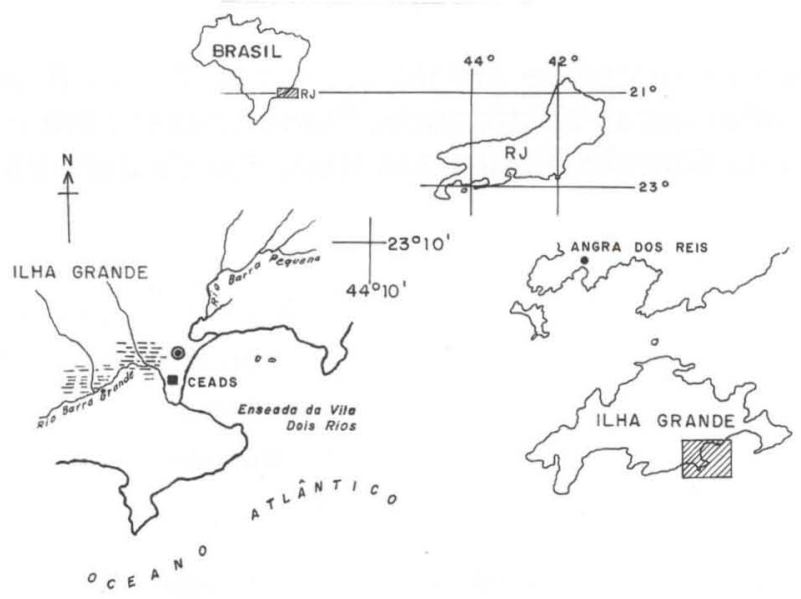

Fig. 1. Localização geográfica da Ilha Grande, mostrando no detalhe o local de coleta. 0 tracejado indica a área alagadiça. ( ๑ ) Vila Dois Rios, ( $\mathbf{\square}$ ) CEADS.

lhadas da morfologia da concha e do sistema reprodutor, indicando como distribuição geográfica Alagoas, Distrito Federal, Goiás, Minas Gerais, Paraná, Pernambuco, Rio Grande do Sul, Santa Catarina e São Paulo.

Sua presença no Estado do Rio de Janeiro foi relatada pela primeira vez por THIENGo et al. (1997) para a Microrregião Serrana. Sua presença na Ilha Grande indica que esta espécie deve estar amplamente distribuída nos ambientes límnicos deste Estado, assim como em outras regiões, passando despercebida devido ao seu pequeno tamanho e a falta de coletas.

$\mathrm{Na}$ Ilha Grande, exemplares da espécie foram coletados em janeiro e março de 1998 na área alagadiça situada atrás da colônia penal, seguindo-se a Trilha da Parnaioca (Fig. 1). O local apresenta grande influência antrópica, representada não só pelas árvores frutíferas como pelo lixo que lá era jogado. Os exemplares foram coletados em locais com pouca movimentação da água, sombreados, especialmente sobre folhas de bananeiras em decomposição.

HAAS (1953) mencionou a ocorrência de Burnupia (Anisancylus) obliquus Brod. \& Sow., 1832 (Laevapecidae) na região, sem precisar exatamente o local da coleta. Entretanto, até o presente, A. nordestensis constitui o único gastrópode límnico encontrado na região do CEADS.

Os exemplares coletados estão depositados nas coleções científicas do Instituto de Biologia Roberto Alcântara Gomes (UERJ) (Col. Mol. UERJ 1359) e da Fundação Instituto Oswaldo Cruz (Col. Mol. IOC/FIOCRUZ 4469).

\section{REFERÊNCIAS BIBLIOGRÁFICAS}

HAAS, F. 1953. Mollusks from Ilha Grande, Brazil. Field. Zool., Chicago, 20 (34): 203-209.

LuCENA, D.T. 1954. Tropicorbis nordestensis n.sp. do Nordeste do Brasil. Rev.

Brasil. Malariol. Doen. Trop., Rio de Janeiro, 6 (3): 329-331.

Revta bras. Zool. 16 (Supl. 2): 257 - 259, 1999 
PARAENSE, W.L. 1975. Estado atual da sistemática dos planorbídeos brasileiros (Mollusca, Gastropoda). Arq. Mus. Nac., Rio de Janeiro, 55: 105-128.

Paraense, W.L. \& N. Deslandes. 1958. The Brazilian species of Drepanotrema. V. D. nordestense (Lucena, 1954). Rev. Brasil. Biol., Rio de Janeiro, 18 (3): 275-281.

ThienGo, S.C.; M.A. FernandeZ; M.F.F. BoAventura \& S.B. SANTOS. 1997. On the occurrence of Biomphalaria straminea in the "Microrregião Serrana" of the State of Rio de Janeiro, Brazil. Ann. 6th International Symposium on Schistosomiasis. Belo Horizonte, p.158. 